\title{
Career alternatives for scientists
}

\author{
More than ever, young PhDs are looking to the biotechnology industry \\ as their first option.
}

\author{
Mark D. Dibner
}

When I completed my $\mathrm{PhD}$ in neurobiology in 1977, biological scientists did not have many significant career alternatives. We were expected to follow in our advisors' footsteps and become academic researchers or some reasonable equivalent thereof. At the time, there were no courses in "survival skills" or career management. Moreover, there were few biological scientists going into industry, as there were then only a handful of biotechnology companies.

A lot has changed over the ensuing two decades. Today, there are about 1,500 biotech companies in the US, employing 145,000 people, over half of them research scientists. And graduate schools have courses aimed at teaching students how to seek jobs outside academia.

\section{An increasing option}

In the past few years, I have addressed 10 different groups of graduate students and postdocs throughout the US to discuss alternative careers and the biotechnology industry. Unlike 1977, when few of us knew scientists who had joined the industry or who had alternative careers because of it, the number of $\mathrm{PhDs}$ who have sought these alternatives today is staggering. My rough assessment of the career choices of $\mathrm{PhD}$ candidates and postdocs is that onequarter wish to stay in academic research, onequarter are seeking a career outside the lab, and half are open to all possibilities, including research careers in academia or industry, or possibly non-research careers.

The main reason for this may be that, today, a career in the biotech industry can no longer be called "alternative." Scientists can pursue their work in applied and even basic research in industry. In the late 1980s and early 1990s, when government RO-1 research grants became harder to obtain, these additional jobs were welcome. Research jobs in the biotech industry have increased in total number every single year since 1988, which is when our Institute of Biotechnology Information (IBI) first began measuring this number.

There are, however, true career alternatives outside of the research track. When Frank Baldino, Jr. was lured away in 1986 from his basic research position at DuPont to found

Mark D. Dibner is president of the Institute for Biotechnology Information, LLC and Strategic Outcomes Services, Inc., P.O. Box 14569,

Research Triangle Park, NC 27709

(mdibner@sosgroup.com).
Cephalon (West Chester, PA), the trend of scientists becoming managers and moving into other types of professional careers was noted in the New York Times. The number and variety of positions available increases as a biotech company grows from being primarily R\&Dbased to requiring internal positions in manufacturing, marketing, business development, human relations, regulatory work, government relations, and management. Scientists who understand the underlying business make ideal candidates for many of these positions.

In addition to these jobs within the industry, there are positions in the huge business sector that has blossomed to support it. For example, scientists have gone on to become patent agents or attorneys, financial analysts, journalists, technical writers, editors, and policymakers, all specializing in biotechnology. An excellent description of different career types can be found in Alternative Careers in Science: Leaving the Ivory Tower (Academic Press, 1998) edited by Cynthia Robbins-Roth, herself a scientist-turned-journalist and consultant. The book tracks the career paths of 22 scientists who have turned to non-research career alternatives, detailing how they chose and entered into these careers.

Other industries also absorb ex-biotech employees. Big pharmaceutical and chemical companies now recognize the experience of working in biotech as being valuable. The huge outsourcing industry of CROs, CMOs, pharmacoeconomics and regulatory firms, and consultancies employs tens of thousands, and a scientific background is often very desirable for employment in these companies.

\section{Job-hunting 101}

How do scientists in training, or even those currently working, go about finding the right job and making themselves desirable to potential employers? While some graduate schools now offer "survival skill" courses, most do not. From my hiring of scientists seeking career changes over the last 12 years, and my own experiences, there are a few pointers that can be shared:

Define what you like to do. If you like to write, plan, manage, create, sell, negotiate, investigate, or whatever, plan a career that can have you doing what you enjoy doing most.

Investigate career paths. You may need to enter a company as a researcher, and move to an alternative career path within the company. Some companies foster this type of move- ment, while others do not-you should ask in advance. Alternatively, you may want to start out in academia to pick up a new technique or technology for a later move to industry. Or, in some cases, another degree, such as an MBA or law degree, may be desirable for where you want to go.

Take your career into your own hands. Many people expect to have jobs and opportunities come to them. There is much investigation that one can do and many contacts to be made. If you decide on a career path, go to a professional society meeting in the target area. Scour the Internet and contact old friends and acquaintances who work in the field or for the company you are targeting. The book Jumpstart Your Career in Bioscience (Peer Productions, 1998) by Chandra B. Louise, another $\mathrm{PhD}$ scientist-turned-clinical development expert, is full of valuable tips for scientists on how to develop their careers.

Do your homework. Never go on an interview without looking at websites, press releases, SEC filings, or any other sources of information on the company you are visiting. I am amazed that over one-third of the applicants for positions at one of my companies have not visited our website, even though all of our ads say "See IBI at http://www.biotechinfo.com." Worse, almost two-thirds of the candidates for postitions at IBI could not even define the word "biotechnology" and had not bothered to look it up before the interview.

Look for opportunities. Biotech firms that have raised a significant amount of seed capital or have just gone public will be hiring. As they grow, they will need to fill many new positions. Industry newsletters, press releases, or other online sources provide this type of information.

\section{Conclusions}

Careers in the biotechnology industry are good careers. They are typically high paying, at least compared to academia, and are highly varied beyond bench science. And, even if a biotechnology company is later downsized or even lost, it usually stays in existence for many years, offering gainful employment for a long time. With the experience gained from working at such a company, people with decent track records and credentials have little trouble finding good jobs within a reasonable amount of time. From our vantage point these jobs will keep growing in number into the next decade. 